Supporting Information for

\title{
Effect of $\mathrm{Ti}^{3+}$ Ions and Conduction Band Electrons
}

\section{on Photocatalytic and Photoelectrochemical Activity \\ of Rutile Titania for Water Oxidation}

Fumiaki Amano $^{a *}$, Masashi Nakata $^{a}$, Akira Yamamoto $^{b}$, and Tsunehiro Tanaka ${ }^{b}$

${ }^{a}$ Department of Chemical and Environmental Engineering, Graduate School of Environmental

Engineering, The University of Kitakyushu, 1-1 Hibikino, Wakamatsu-ku, Kitakyushu 808-0135, Japan.

${ }^{b}$ Department of Molecular Engineering, Graduate School of Engineering, Kyoto University, Kyoto Daigaku Katsura, Nishikyo-ku, Kyoto 615-8510, Japan. 
Table S1. Physical properties and photocatalytic activities of commercial $\mathrm{TiO}_{2}$ particles.

\begin{tabular}{|c|c|c|c|c|c|}
\hline sample & supplier & $X_{\mathrm{R}}^{\mathrm{a}}(\mathrm{wt} \%)$ & $\begin{array}{c}S S A^{\mathrm{b}} \\
\left(\mathrm{m}^{2} \mathrm{~g}^{-1}\right)\end{array}$ & $\begin{array}{c}\mathrm{Ag}^{+} \text {on } \mathrm{TiO}_{2}{ }^{\mathrm{c}} \\
\left.(\mu \mathrm{mol} \mathrm{g})^{-1}\right)\end{array}$ & $\begin{array}{c}r\left(\mathrm{O}_{2}\right)^{\mathrm{d}} \\
\left(\mu \mathrm{mol} \mathrm{h}^{-1}\right)\end{array}$ \\
\hline $\begin{array}{l}\text { rutile } \mathrm{TiO}_{2} \\
\text { (R-Kojundo) }\end{array}$ & $\begin{array}{c}\text { Kojundo Chemical } \\
\text { Laboratory } \\
\text { (Sakado, Japan) }\end{array}$ & 97 & 2.3 & 1.8 & 44 \\
\hline P25 & $\begin{array}{c}\text { Nippon Aerosil } \\
\text { (Yokkaichi, Japan) }\end{array}$ & 13 & 55 & 34 & 3.1 \\
\hline FP-6 & $\begin{array}{l}\text { Showa Titanium } \\
\text { (Toyama, Japan) }\end{array}$ & 7.5 & 103 & 28 & 0.7 \\
\hline anatase $\mathrm{TiO}_{2}$ & $\begin{array}{c}\text { Kanto Chemical } \\
\text { (Tokyo, Japan) }\end{array}$ & 0.0 & 17 & 7.7 & 0.9 \\
\hline
\end{tabular}

a) Weight fraction of rutile in the anatase-rutile mixture, b) BET specific surface area, c) the amount of $\mathrm{Ag}^{+}$ion adsorbed on $\mathrm{TiO}_{2}$ in dark, d) rate of photocatalytic $\mathrm{O}_{2}$ evolution by water oxidation over 50-mg $\mathrm{TiO}_{2}$ in the presence of $\mathrm{AgNO}_{3}$, and e) Degussa (Evonik) P25. 


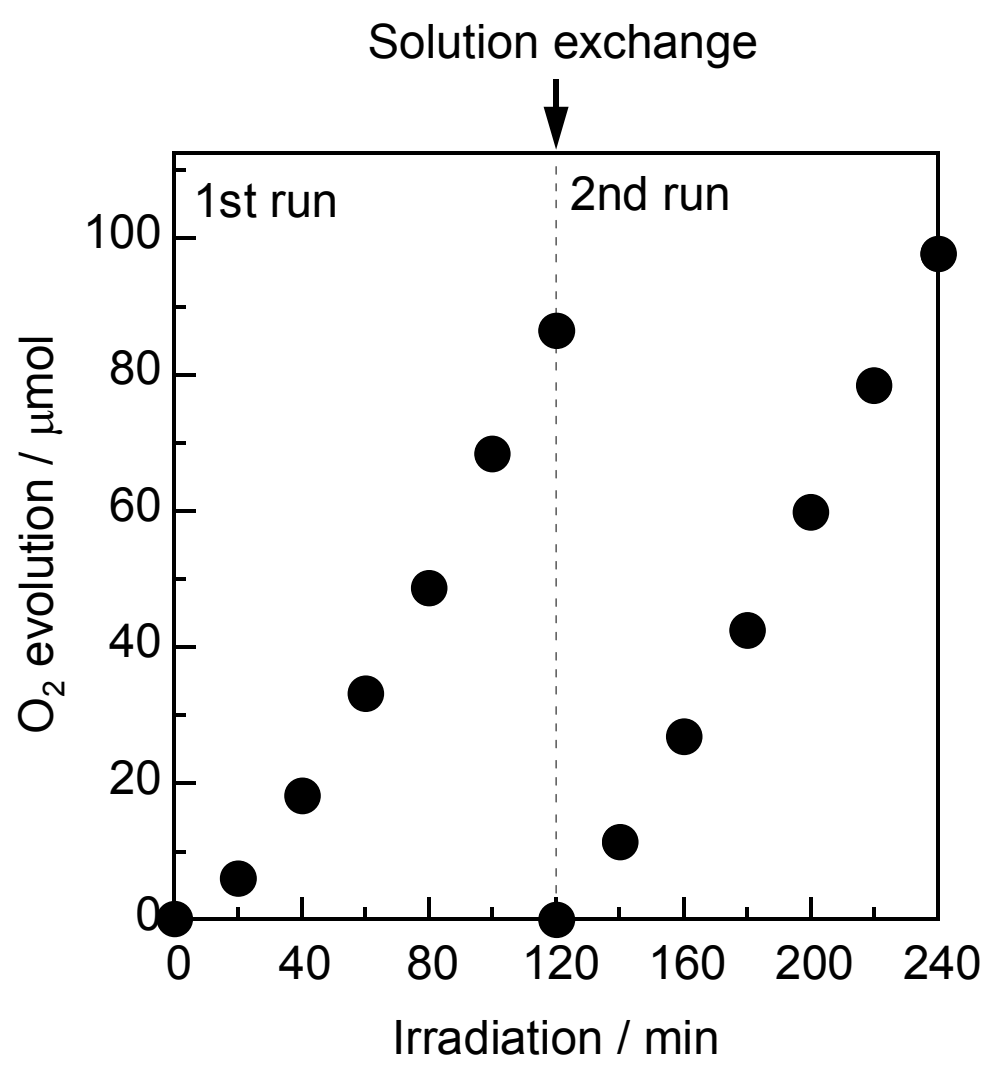

Figure S1. Time course for the photocatalytic $\mathrm{O}_{2}$ evolution by water oxidation in the presence of sacrificial $\mathrm{AgNO}_{3}$ over R-Kojundo. The solution was changed after irradiation for 120 min due

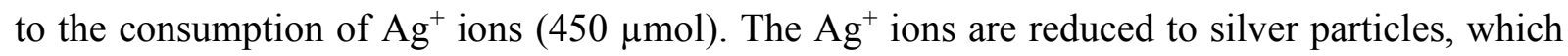
are deposited on $\mathrm{TiO}_{2}$ surface. The $r\left(\mathrm{O}_{2}\right)$ was not affected by the decrease of the $\mathrm{Ag}^{+}$concentration and the deposition of silver particles. 


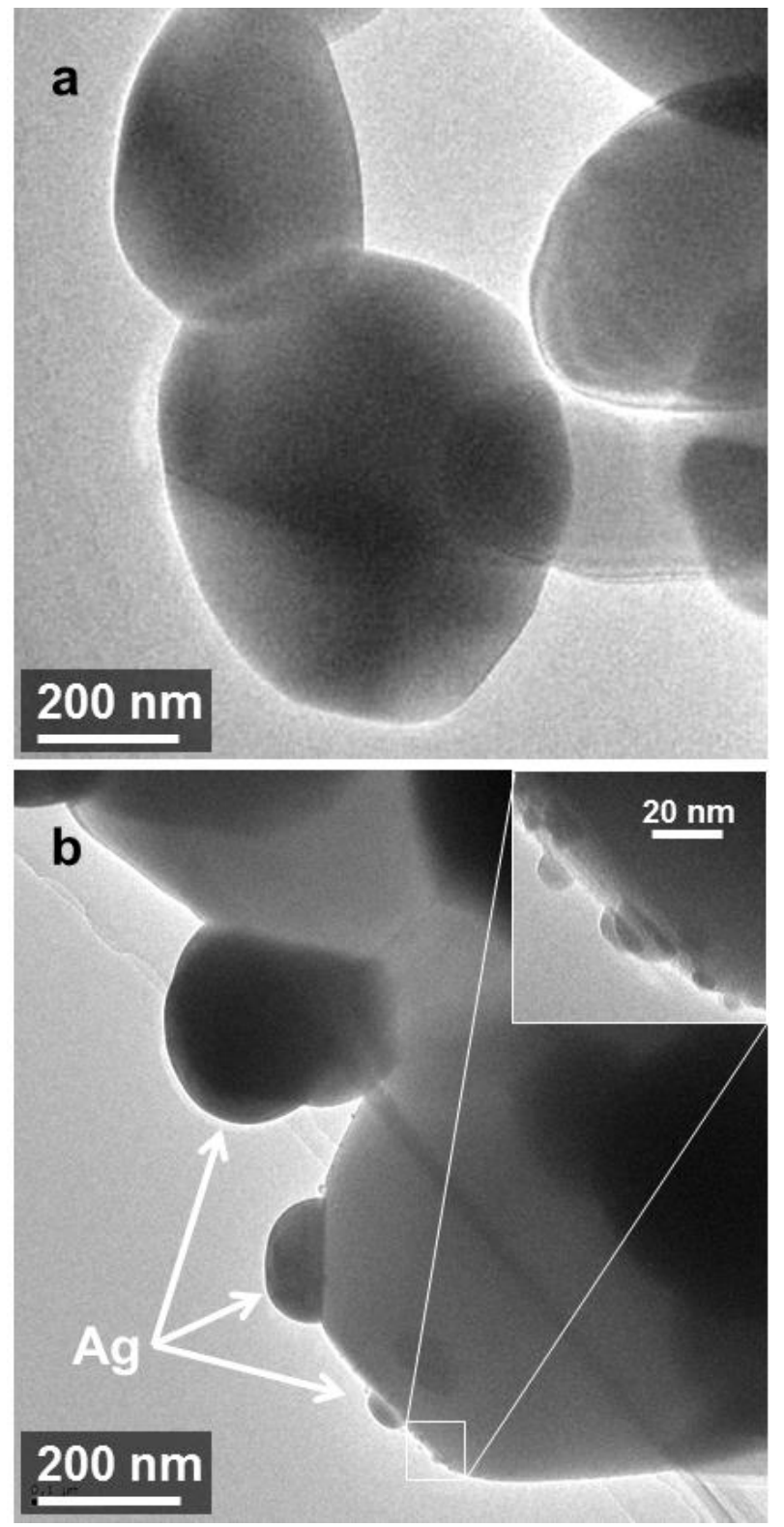

Figure S2. TEM images of R-Kojundo (a) before and (b) after photocatalytic $\mathrm{O}_{2}$ evolution for $120 \mathrm{~min}$. The amount of photodeposited $\mathrm{Ag}^{0}$, which was measured by ICP-OES after dissolving with $\mathrm{HNO}_{3}$, was consistent with the stoichiometric amount calculated from the evolved $\mathrm{O}_{2}(4$ electrons are required for the evolution of one molecule of $\mathrm{O}_{2}$ ). 


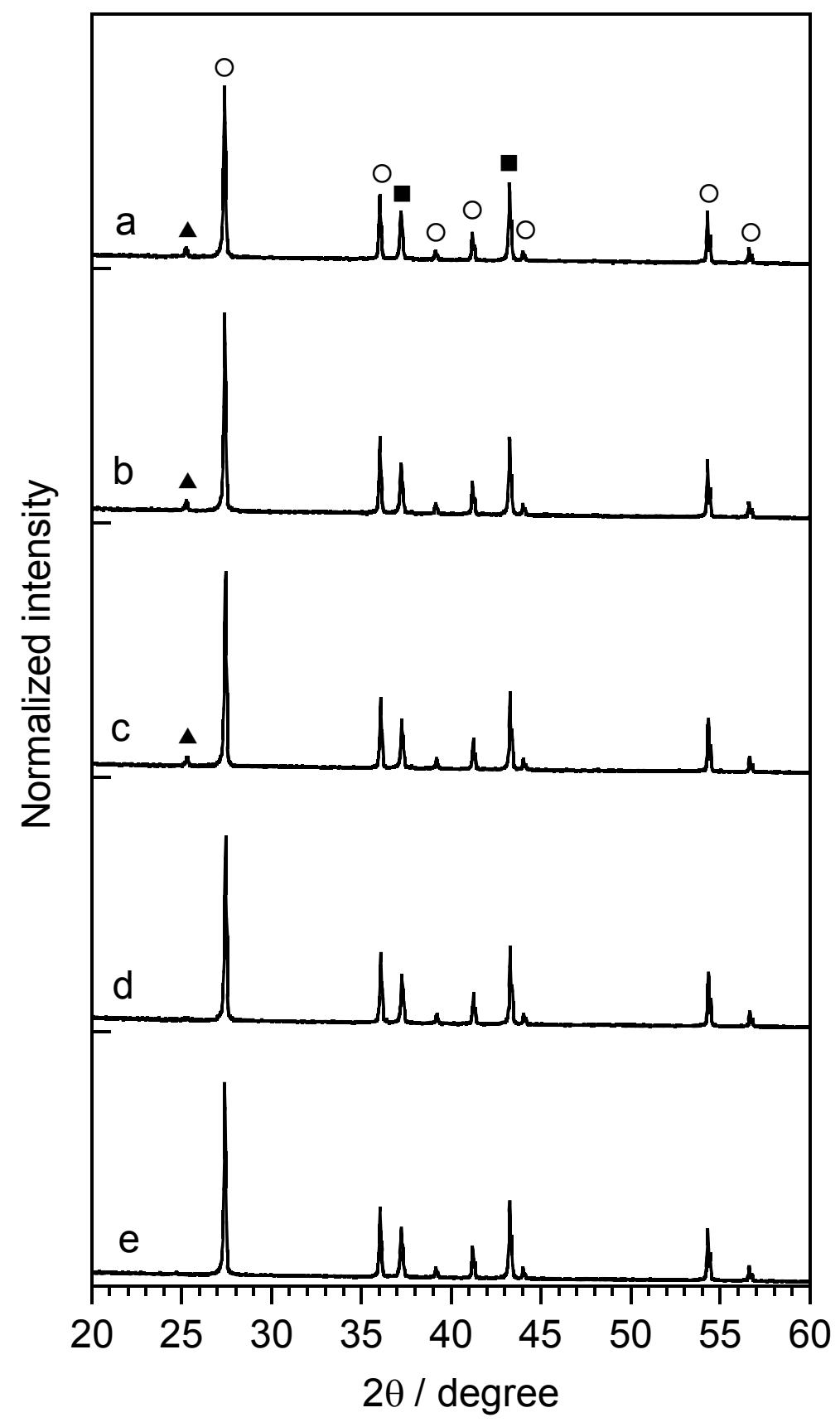

Figure S3. XRD patterns of (a) R-Kojundo, (b) R500, (c) R700, (d) R900, and (e) R1100: (o) rutile $\mathrm{TiO}_{2},(\boldsymbol{\Delta})$ anatase $\mathrm{TiO}_{2}$, and ( $\left.\mathbf{\square}\right) \mathrm{NiO}$ mixed as an internal standard. The patterns have been translated in the Y-axis for clarity. 


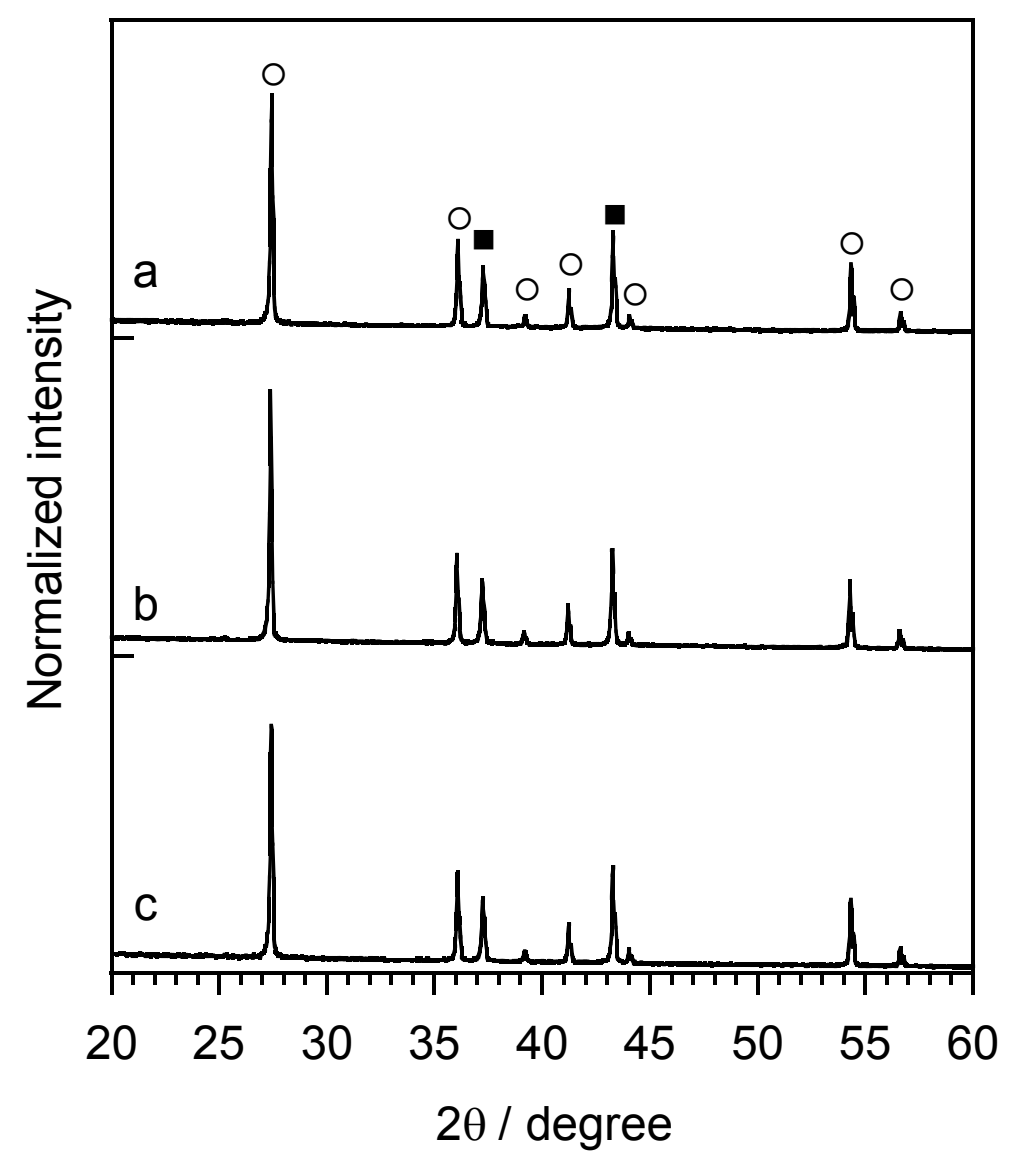

Figure S4. XRD patterns of (a) R900, (b) R900-H500, and (c) R900-H700: (o) rutile $\mathrm{TiO}_{2}$ and (घ) $\mathrm{NiO}$ mixed as an internal standard. The patterns have been translated in the Y-axis for clarity. 


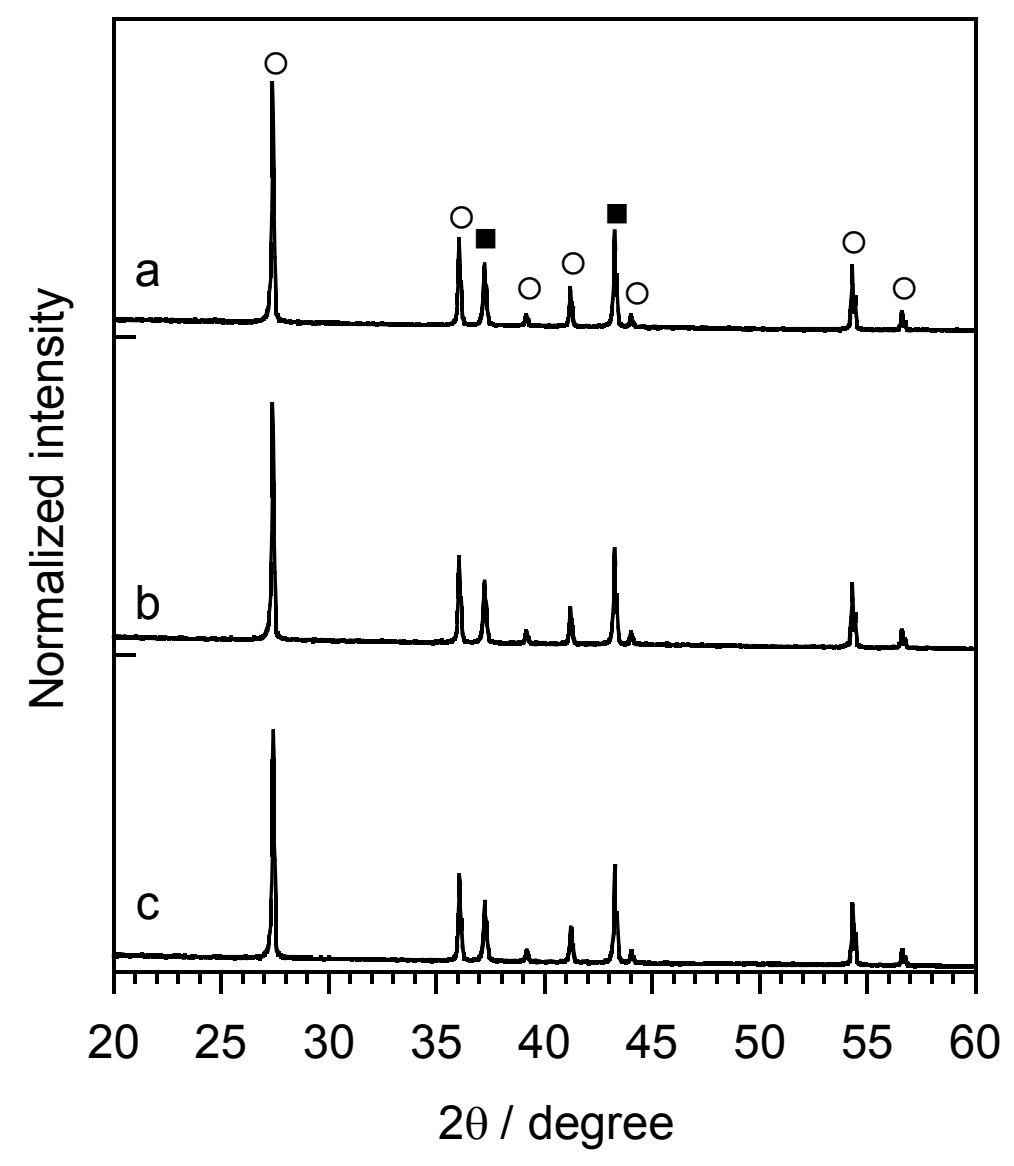

Figure S5. XRD patterns of (a) R1100, (b) R1100-H500, and (c) R1100-H700: (o) rutile $\mathrm{TiO}_{2}$ and ( $\mathbf{a}) \mathrm{NiO}$ mixed as an internal standard. The patterns have been translated in the Y-axis for clarity. 


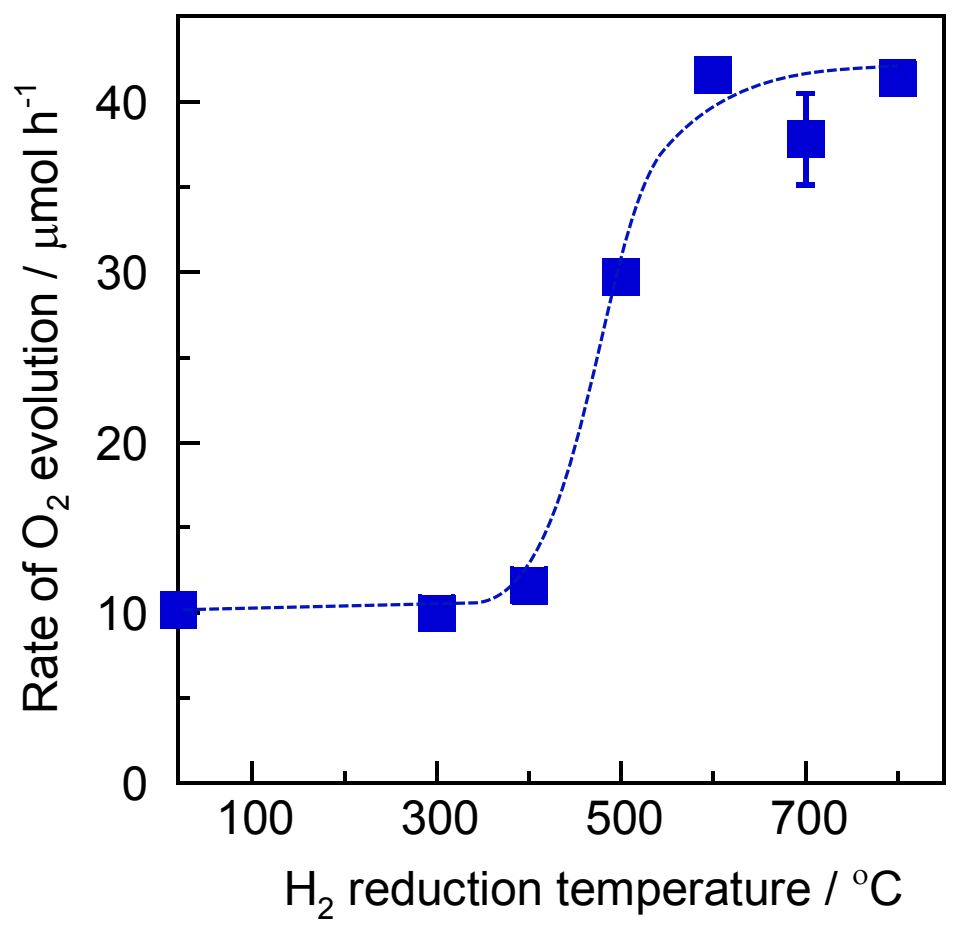

Figure S6. Effect of temperature of $\mathrm{H}_{2}$ treatment on the rate of photocatalytic $\mathrm{O}_{2}$ evolution of R1100. 

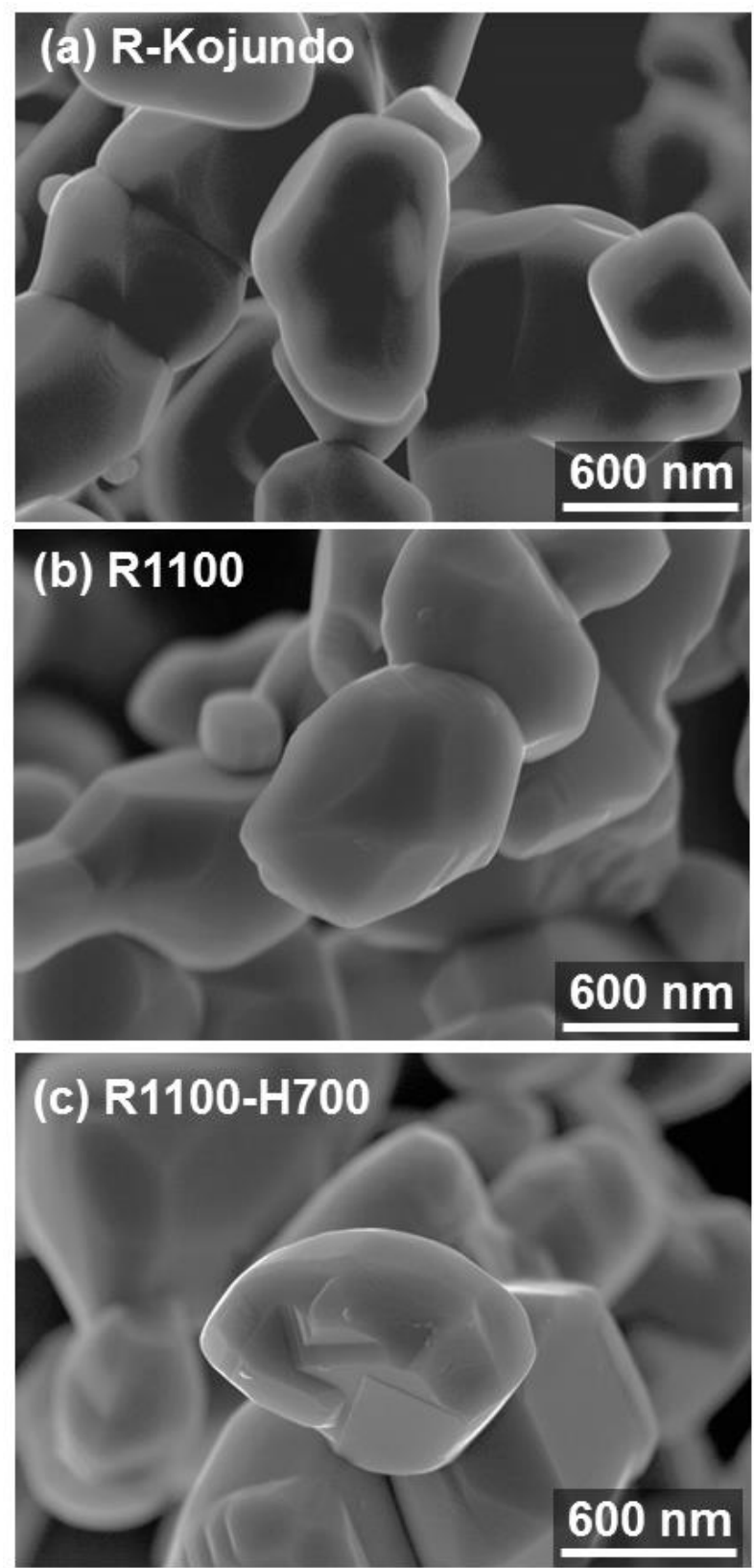

Figure S7. FE-SEM images of (a) R-Kojundo, (b) R1100, and (c) R1100-H700. 

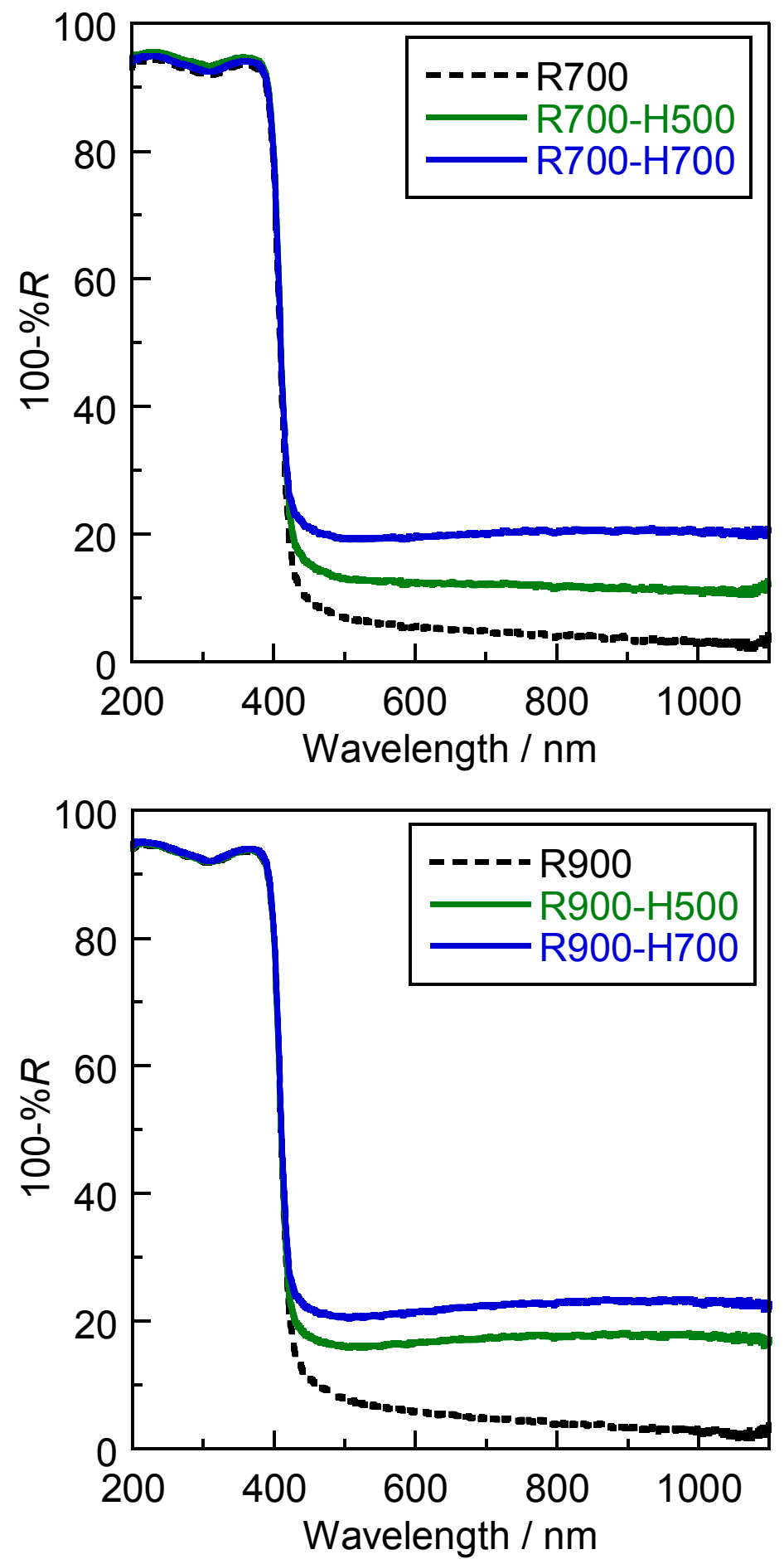

Figure S8. Diffuse reflectance UV-Vis-NIR spectra of $\mathrm{TiO}_{2}$ : (a) R700, (b) R700-H500, (c) R700-H700, (d) R900, (e) R900-H500, and (f) R900-H700. 


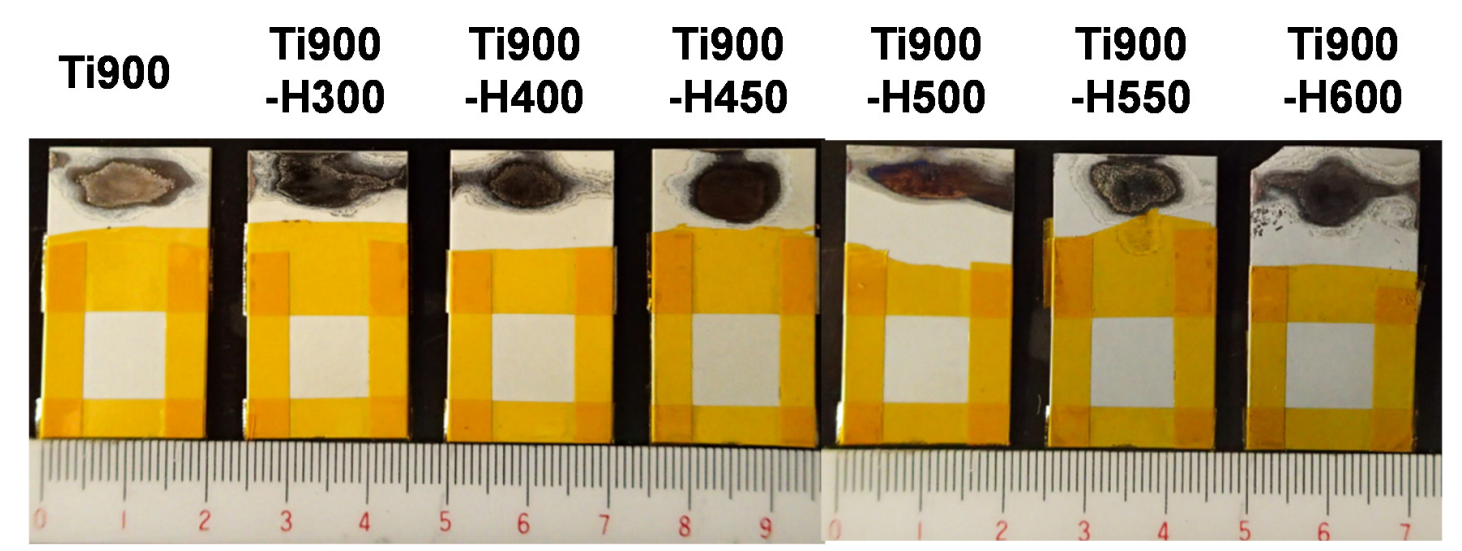

Figure S9. Pictures of thermally oxidized $\mathrm{TiO}_{2}$ films on titanium sheet. 


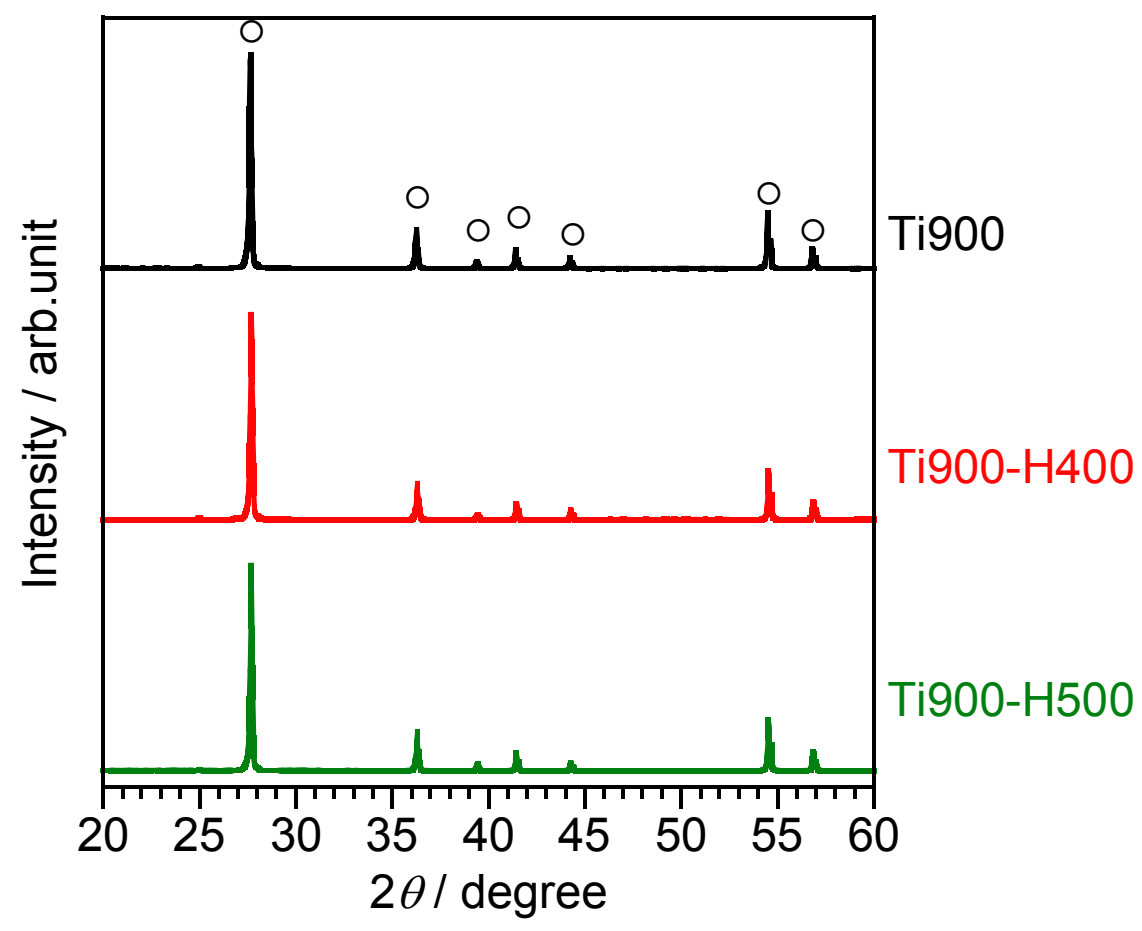

Figure S10. XRD patterns of (a) Ti900, (b) Ti900-H500, and (c) Ti900-H700: (o) rutile $\mathrm{TiO}_{2}$. The patterns have been translated in the Y-axis for clarity. 


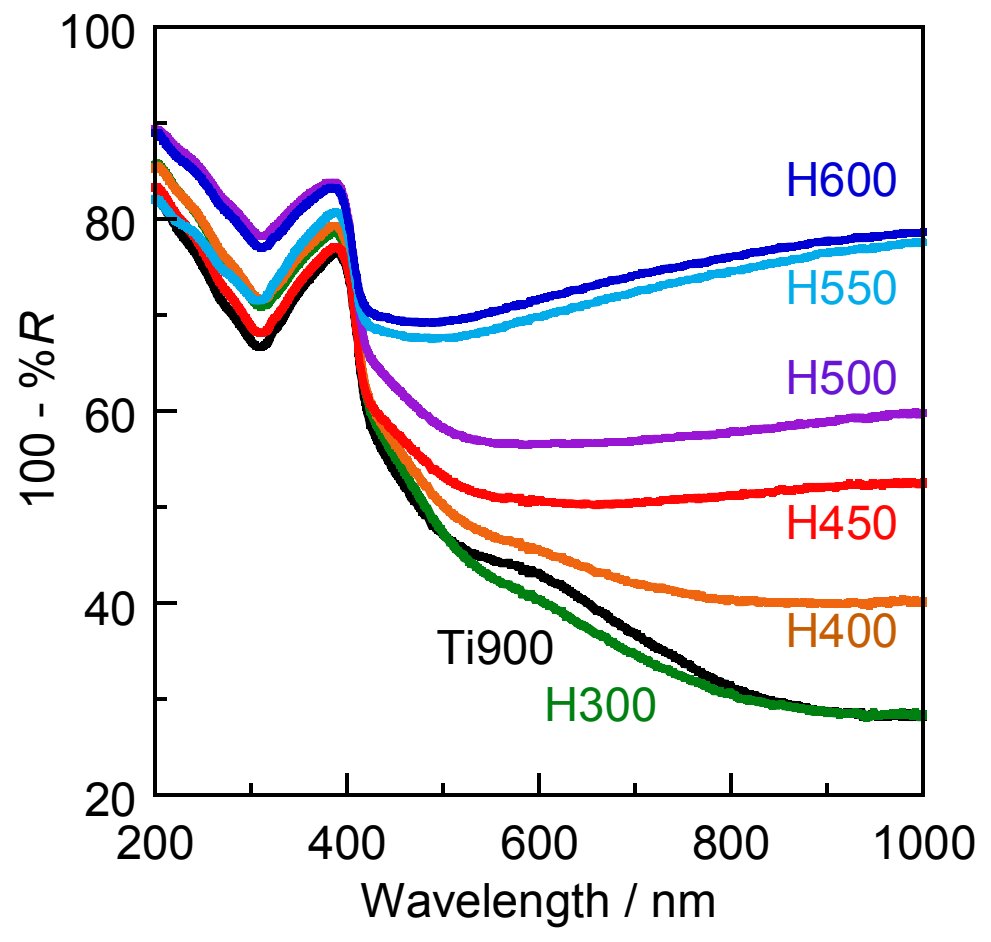

Figure S11. Diffuse reflectance UV-Vis-NIR spectra of thermally oxidized $\mathrm{TiO}_{2}$ films on titanium sheet. 

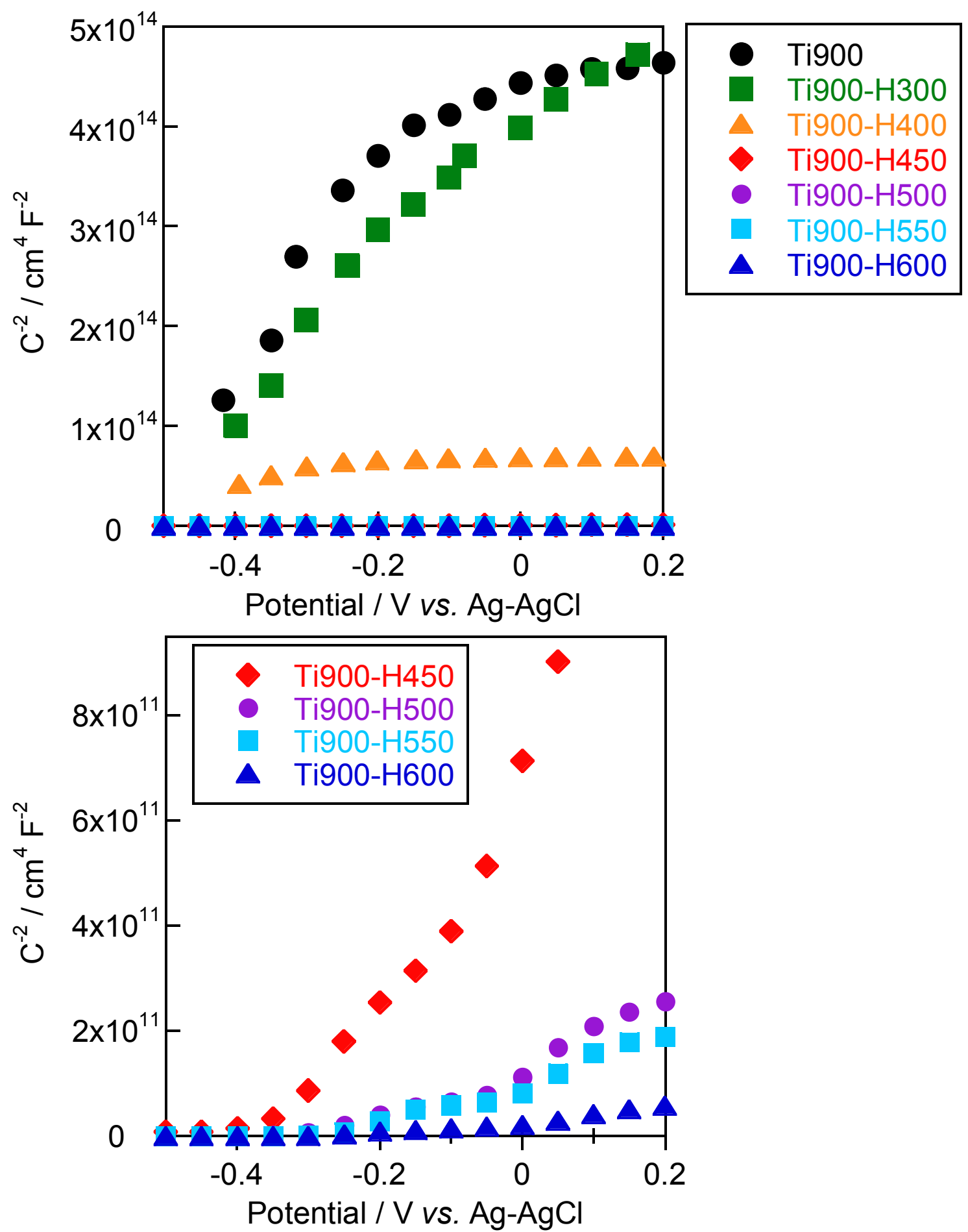

Figure S12. Mott-Schottky plots of thermally oxidized $\mathrm{TiO}_{2}$ films on titanium sheet in $0.1 \mathrm{~mol}$ $\mathrm{L}^{-1} \mathrm{H}_{2} \mathrm{SO}_{4}(\mathrm{pH}=1)$. 

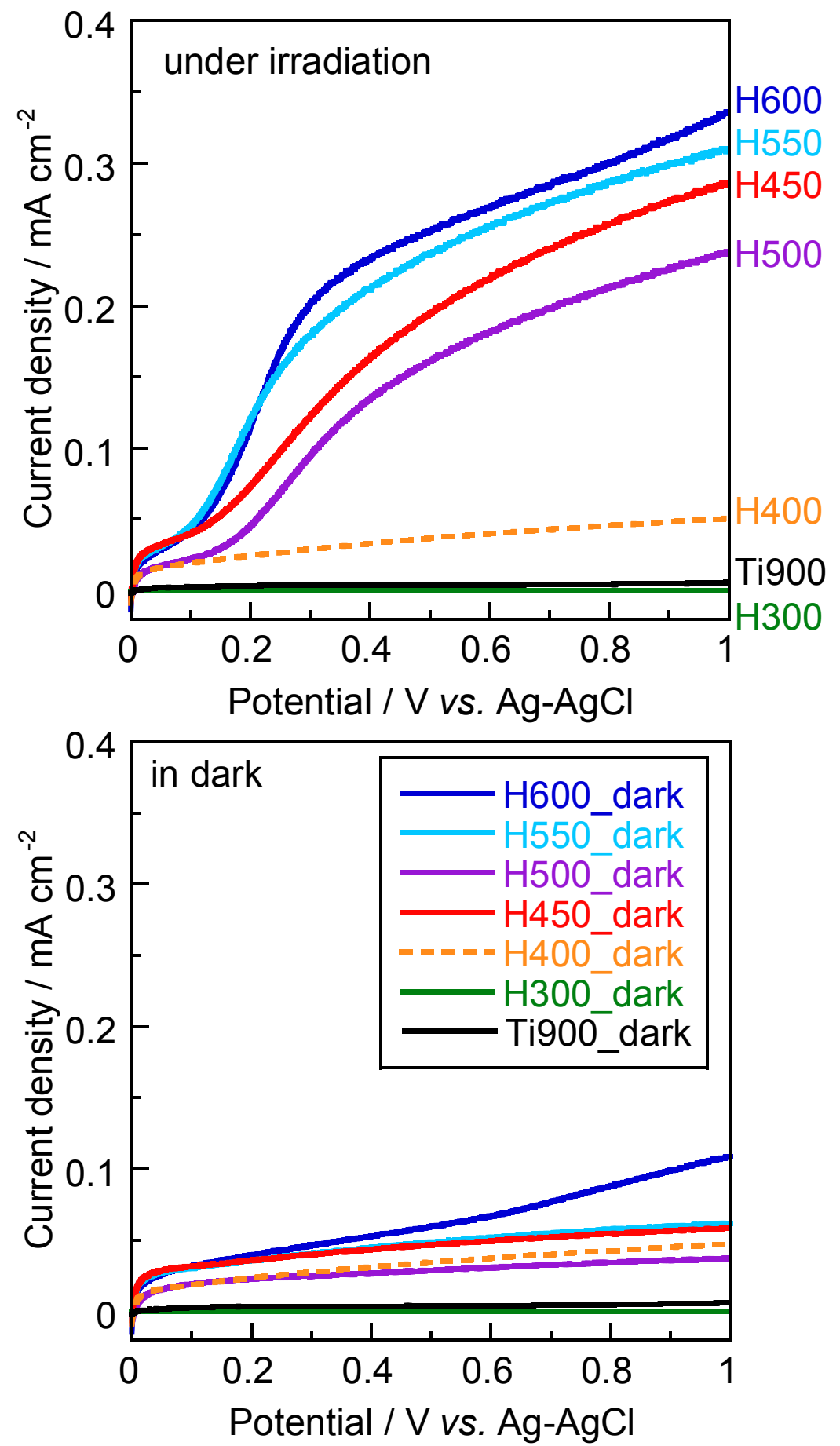

Figure S13. Current density-anodic potential curves of thermally oxidized $\mathrm{TiO}_{2}$ films in 0.1 mol L ${ }^{-1} \mathrm{H}_{2} \mathrm{SO}_{4}(\mathrm{pH}=1)$ under photoirradiation and in dark. 


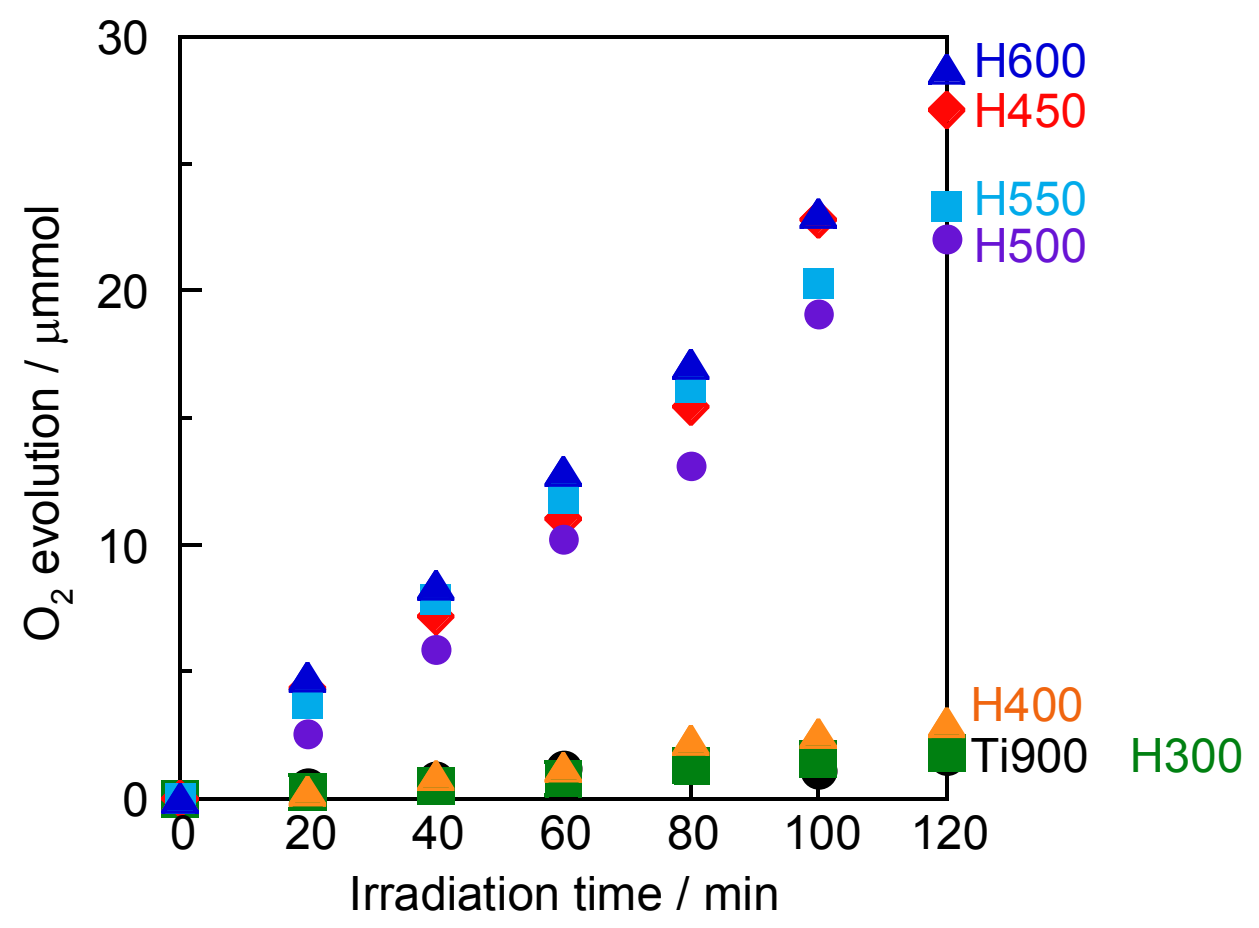

Figure S14. Rate of photocatalytic $\mathrm{O}_{2}$ evolution by water oxidation in the presence of sacrificial $\mathrm{AgNO}_{3}$ over thermally oxidized $\mathrm{TiO}_{2}$ films on titanium sheet. 